\title{
ChemComm
}

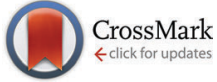

Cite this: Chem. Commun., 2014 50, 13254

Received 24th July 2014,

Accepted 3rd September 2014

DOI: $10.1039 / c 4 c c 05773 b$

www.rsc.org/chemcomm

\section{A trio of nanoswitches in redox-potential controlled communication $\dagger$}

\author{
Susnata Pramanik, Soumen De and Michael Schmittel*
}

\begin{abstract}
A potential-controlled two-step bidirectional communication protocol between the nanoswitches $[\mathrm{Cu}(1)]^{+}, 2$ and 3 is set up, in which ligand followed by metal-ion oxidation drives two subsequent metal ion translocations (self-sorting) changing the switching state at each switch. The communication is reset to its starting point by a two-electron reduction.
\end{abstract}

Life processes are sustained through intricate communication and signaling networks involving recognition, processing and amplification of information, sometimes through cascading pathways. ${ }^{1}$ While multistep signaling, such as in the metallothionein protein, ${ }^{2}$ is often encountered in biology, artificial switches ${ }^{3}$ or machines ${ }^{4}$ are rarely networked by chemical communication, ${ }^{5}$ and if, they are engaged in single-step protocols. ${ }^{6}$ Intermolecular communication involving major rearrangement at two switches has been reported by the group of Aprahamian ${ }^{6 c}$ and more recently by us. ${ }^{6 d}$ In the former case, being reminiscent of a biological proton relay, binding of $\mathrm{Zn}^{2+}$ ions induced a toggling at the first switch triggering proton release, which stimulated a change in the switching state at the second switch. Our recent work ${ }^{6 d}$ demonstrated bidirectional reversible communication between the nanoswitches 2 and 3 using redox equivalents as input signals (Scheme 1). The strategy was based on two orthogonal ${ }^{7}$ coordination scenarios developed by us over the years. Switch 2 equipped with its intramolecular bipyridine and phenanthroline (HETPHEN ${ }^{8}$ ) coordination site prefers $\mathrm{Cu}^{+}$ions, whereas 3 with its terpyridine and phenanthroline $\left(\right.$ HETTAP $^{8}$ ) binding motif favours $\mathrm{Cu}^{2+}$ or $\mathrm{Zn}^{2+} .9$ Due to these preferences, the nanoswitch duo $[\mathrm{Cu}(2)]^{+}$and 3 experienced a copper translocation generating 2 and $[\mathrm{Cu}(3)]^{2+}$ upon oxidation, while the starting point was reset by reduction. ${ }^{6 d}$

Here, we describe a two-step bidirectional communication protocol between the three nanoswitches 1-3 using two subsequent

Center of Micro and Nanochemistry and Engineering, Organische Chemie I,

Universität Siegen, Adolf-Reichwein-Str. 2, D-57068 Siegen, Germany.

E-mail:schmittel@chemie.uni-siegen.de

$\dagger$ Electronic supplementary information (ESI) available: Synthesis, characterisation, and switching studies. See DOI: 10.1039/c4cc05773b
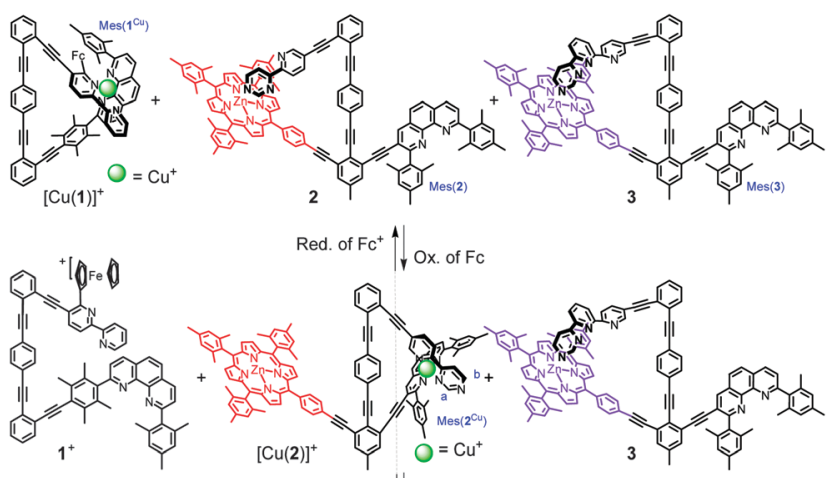

Red. of $\mathrm{Fc}^{+} \mid$r Ox. of Fc
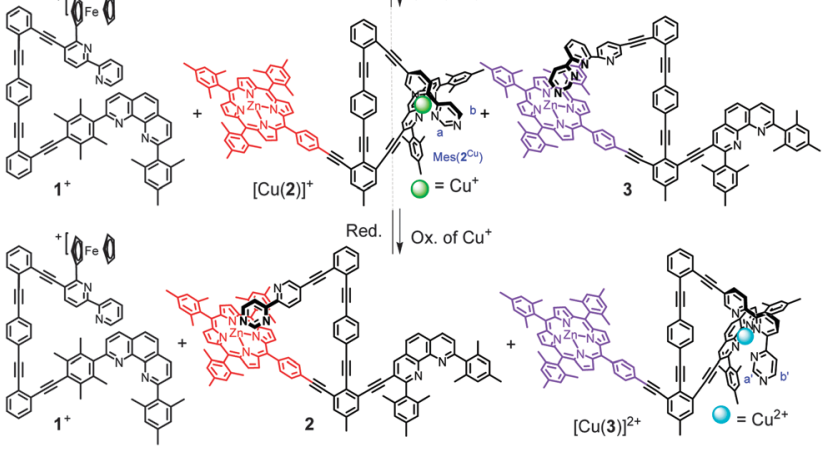

Scheme 1 Reversible cascade switching among three nanoswitches.

one-electron redox inputs. Despite integrating an already reported redox-controlled communication scenario, i.e. between switches 2 and $3,{ }^{6 d}$ the realisation of two-step communication between the trio 1-3 adds a new level of complexity requiring to devise a perfectly matching nanoswitch $\mathbf{1}$ and a potential control for the two-step translocation. The key criteria for our design were: (1) the two oxidation steps have to occur at separate potentials each followed by a clean self-sorting ${ }^{10}$ propelling the communication cascade. (2) The new electron-rich switch 1 should have a higher affinity toward $\mathrm{Cu}^{+}$than the known HETPHEN- and HETTAPbased switches 2 and 3 and (3) the lowest oxidation potential. (4) After oxidation, nanoswitch 1 should be the weakest binding ligand for $\mathrm{Cu}^{+}$and (5) also should rapidly release $\mathrm{Cu}^{+}$.

Taking all the requirements into account, we considered 2-ferrocenyl-[1,10]-phenanthroline and 6-ferrocenyl-2,2'-bipyridine as possible binding motifs in 1, expecting that the electrondonating ferrocenyl group ${ }^{11}$ next to the chelate site would not only provide a sizeable gain in binding strength but also ensure 
release of the metal ion upon oxidation of the ferrocene. In an initial screening, 2,9-dimesityl-[1,10]-phenanthroline provided a stronger binding heteroleptic copper(I) complex in combination with 2-ferrocenylphenanthroline, but after oxidation copper remained strongly bound. As a result, we turned to 6-ferrocenyl-2,2'-bipyridine despite its lower binding quality for $\mathrm{Cu}^{+}$.

Based on these considerations, we devised a new nanoswitch 1 following our successful triangular design ${ }^{12}$ (Scheme 1), expecting the kinetics of metal-ion release to be fast. Its main competitor for $\mathrm{Cu}^{+}$, i.e. nanoswitch 2 , should be at disadvantage in the competition, because copper(I) complexation at $\mathbf{2}$ goes along with loss of the pyrimidine $\rightarrow$ zinc(II) porphyrin interaction.

While the preparation of nanoswitches $2^{12 b}$ and $3^{6 d}$ has been reported previously, nanoswitch 1 was synthesised in $60 \%$ yield from its direct precursor via a Sonogashira coupling (for details, see the ESI $\dagger$ ). Upon reacting switch $\mathbf{1}$ with $\mathrm{Cu}^{+}$, the ferrocene protons at the substituted cyclopentadienyl ring lost their symmetry and shifted upfield to 3.32, 3.67, 4.54 and $4.92 \mathrm{ppm}$ in the ${ }^{1} \mathrm{H}$ NMR spectrum due to the proximity of the shielding phenanthroline. Additionally, the mesityl protons shifted upfield to 6.35 and $6.43 \mathrm{ppm}$ (Fig. S5, ESI $\dagger$ ). The ESI-MS spectrum displays a single peak at $\mathrm{m} / \mathrm{z}=1155.5 \mathrm{Da}$ with its isotopic distribution exactly matching the theoretical one of complex $[\mathrm{Cu}(\mathbf{1})]^{+}$(Fig. S7, ESI $\dagger$ ).

The cyclic voltammograms show fully reversible redox $\mathrm{Fc}^{0 /+}$ waves for $\mathbf{1}^{0 /+}$ at $E_{1 / 2}=450 \mathrm{mV}_{\mathrm{SCE}}$ (Fig. S3, ESI $\dagger$ ) and for [Cu(1) $]^{+/ 2+}$ at $E_{1 / 2}=610 \mathrm{mV}_{\mathrm{SCE}}$, while $\mathrm{Cu}^{+/ 2+}$ oxidation in $[\mathrm{Cu}(\mathbf{1})]^{2+/ 3+}$ emerged at $E_{1 / 2}=940 \mathrm{mV}_{\mathrm{SCE}}$ (Fig. S6, ESI $\dagger$ ). On the basis of the data, we found that $\mathrm{Cu}^{+}$is less strongly bound in $[\mathrm{Cu}(\mathbf{1})]^{2+}$ than in $[\mathrm{Cu}(\mathbf{1})]^{+}$by $\Delta \log K=2.7$.

As a model for paramagnetic $[\mathrm{Cu}(\mathbf{1})]^{2+}$, we characterised diamagnetic $[\mathrm{Zn}(\mathbf{1})]^{2+}$, prepared from stoichiometric amounts of $\mathbf{1}$ and $\mathrm{Zn}(\mathrm{OTf})_{2}$. The splitting patterns of the diagnostic protons are similar as for $[\mathrm{Cu}(\mathbf{1})]^{+}$but they appear at different positions in the ${ }^{1} \mathrm{H}$ NMR spectrum. For instance, protons from the substituted cyclopentadienyl ring of ferrocene appear at 3.35, 3.84, 4.37 and $5.48 \mathrm{ppm}$. Moreover, mesityl protons are shifted to 6.03 and $6.43 \mathrm{ppm}$ (Fig. S8, ESI†). Formation of the complex was also proved from ESI-MS data with a peak at $m / z=578.6 \mathrm{Da}$ and an isotopic distribution matching the one expected for $[\mathrm{Zn}(\mathbf{1})]^{2+}$ (Fig. S9, ESI†).

To address the first step of the new communication protocol, switches 1 and 2 were treated with $\mathrm{Cu}^{+}(1: 1: 1)$. After equilibration at $40{ }^{\circ} \mathrm{C}$ for a few minutes, $90 \%$ of copper(I) was found on $[\mathrm{Cu}(\mathbf{1})]^{+}$(Fig. 1a). The selectivity was ascertained from ${ }^{1} \mathrm{H}$ NMR and UV-Vis data. Reciprocally, addition of switch $\mathbf{1}$ to a solution of $[\mathrm{Cu}(2)]^{+}(2.70 \mathrm{mM})$ led to the same results as documented by the appearance of new signals at 2.87 and $3.31 \mathrm{ppm}$ being typical for the free nanoswitch 2 with its pyrimidine ring being immersed into the shielding current of the zinc porphyrin ring (Fig. S11, ESI $\dagger$ ). At the same time, emergence of signals at 3.32, 3.67, 4.54 and $4.92 \mathrm{ppm}$ along with upfield shifted mesityl protons (6.35 and 6.43 ppm) suggests formation of $[\mathrm{Cu}(\mathbf{1})]^{+}$. For the communication step $[\mathrm{Cu}(2)]^{+}+\mathbf{1}$, the NMR spectrum shows that full equilibrium was reached $58 \mathrm{~min}$ after mixing at room temperature (Fig. S12, ESI $\dagger$ ). At a lower concentration $(c=0.1 \mathrm{mM})$ metal translocation from $[\mathrm{Cu}(2)]^{+}$to 1 , followed by UV-Vis spectroscopy at room temperature, took over a day to reach the equilibrium (Fig. S13, ESI $†$ ).

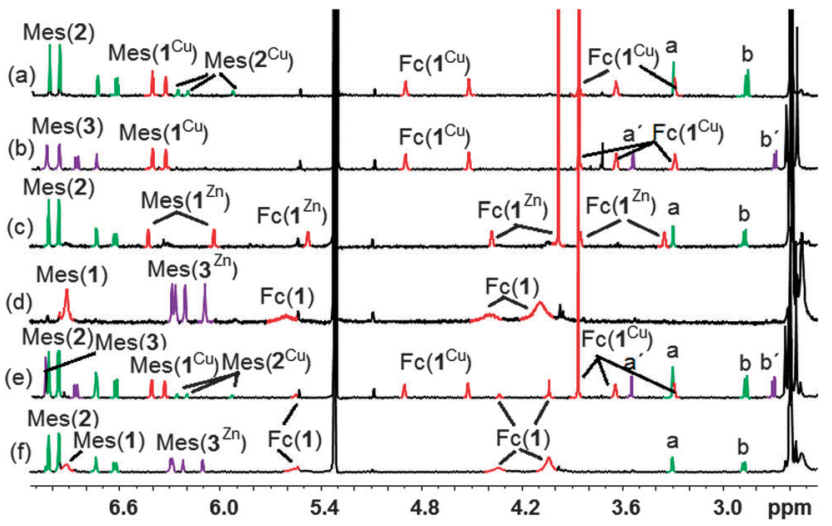

Fig. 1 Partial ${ }^{1} \mathrm{H}$ NMR spectra ( $400 \mathrm{MHz}, \mathrm{CD}_{2} \mathrm{Cl}_{2}, 298 \mathrm{~K}$ ) of switches $1-3$ in the presence of metal ions after equilibration. The traces represent: (a) Formation of a $90: 10$ ratio of $[\mathrm{Cu}(\mathbf{1})]^{+}$and $[\mathrm{Cu}(\mathbf{2})]^{+}$from a $1: 1: 1$ mixture of $\mathbf{1}, \mathbf{2}$ and $\mathrm{Cu}^{+}$. (b) Sole formation of $[\mathrm{Cu}(\mathbf{1})]^{+}$from a 1:1:1 mixture of $\mathbf{1}$, 3 and $\mathrm{Cu}^{+}$. (c) Exclusive formation of $[\mathrm{Zn}(\mathbf{1})]^{2+}$ from a 1:1:1 mixture of $\mathbf{1}$, 2 and $\mathrm{Zn}^{2+}$. (d) Complete formation of $[\mathrm{Zn}(\mathbf{3})]^{2+}$ from a 1:1:1 mixture of $\mathbf{1}$, 3 and $\mathrm{Zn}^{2+}$. (e) Mixing of 1, 2, 3 and $\mathrm{Cu}^{+}(1: 1: 1: 1)$ generates $90 \%$ of $[\mathrm{Cu}(\mathbf{1})]^{+}$and $10 \%$ of $[\mathrm{Cu}(2)]^{+}$leaving 3 free in solution. (f) Exclusive formation of $[\mathrm{Zn}(\mathbf{3})]^{2+}$ when $\mathbf{1}, \mathbf{2}, \mathbf{3}$ and $\mathrm{Zn}^{2+}(1: 1: 1: 1)$ were mixed.

The exclusive selectivity for $[\mathrm{Cu}(\mathbf{1})]^{+}$over switch $\mathbf{3}$ is warranted due to the fact that $\mathbf{2}$ has a much higher binding constant for $\mathrm{Cu}^{+}$than switch 3 (Fig. S14, ESI $\dagger$ ). For a kinetic analysis, we used UV-Vis spectroscopy (Fig. S15, ESI $\dagger$ ) at $c=0.1 \mathrm{mM}$, because the metal-ion transfer is readily detectable due to the reorganisation of the azaterpyridine arm from the phenanthroline to the zinc porphyrin station. Addition of $\mathbf{1}$ to a solution of $[\mathrm{Cu}(3)]^{+}$at room temperature entailed a shift of the $\mathrm{Q}$ band absorption from 550 to $561 \mathrm{~nm}$ within $3 \mathrm{~min}$ in dichloromethane (DCM).

We chose $\mathrm{Zn}^{2+}$ as a diamagnetic input to check the face-to-face preferences of the switches for $\mathrm{Cu}^{2+}$. Although in the competition between nanoswitches $\mathbf{1}$ and $\mathbf{2}$, it was complex $[\operatorname{Zn}(\mathbf{1})]^{2+}$ that formed exclusively with switch 2 remaining untouched (Fig. 1c and Fig. S16, $\mathrm{ESI}+$ ), the pentacoordinated complex $[\mathrm{Zn}(3)]^{2+}$ was afforded as a single product (Fig. 1d and Fig. S17, ESI $\dagger$ ) from a mixture of 1, 3 and $\mathrm{Zn}^{2+}(1: 1: 1)$. The latter result is quite surprising because formation of $[\operatorname{Zn}(3)]^{2+}$ goes along with the loss of a azaterpyridine $\rightarrow$ zinc(II)porphyrin interaction. The outcome thus reflects the low stability of tetracoordinated zinc(II) ions. Indeed, the typical ${ }^{1} \mathrm{H}$ NMR signals of the free switch 1 were preserved at 4.06, 4.32 and $5.57 \mathrm{ppm}$ (from the ferrocene unit), whereas the diagnostic mesityl protons of switch 3 shifted upfield and splitted into four sets appearing at $6.07,6.18,6.24$, and $6.27 \mathrm{ppm}$. The same set of signals is seen in the separately prepared $[\mathrm{Zn}(3)]^{2+}$ complex. ${ }^{6 d}$ Thus, $\mathrm{Cu}^{2+}$, due to its similar coordination demands as $\mathrm{Zn}^{2+}$, should bind selectively to nanoswitch $\mathbf{3}$ over $\mathbf{1}$ and even more over $\mathbf{1}^{+}$.

Because of the rather slow rate preventing a kinetic study using cyclic voltammetry, we initiated redox-triggered communication by adding $\mathbf{T B P A}^{+\mathbf{*}} \mathrm{SbCl}_{6}{ }^{-}$(tris(4-bromophenyl)aminium hexachloroantimonate) for oxidation and dmfc (decamethylferrocene) for reduction. To evaluate the subsequent step, a solution of $[\mathrm{Cu}(\mathbf{1})]^{+}$ and 2 (at 1:1 ratio, $0.1 \mathrm{mM}$ ) in DCM was treated with one equivalent of $\mathbf{T B P A}^{+\boldsymbol{*}} \mathrm{SbCl}_{6}{ }^{-}$. As a result, the $\mathrm{Q}$ band of 2 shifted from 561 to $550 \mathrm{~nm}$ and became constant after $4 \mathrm{~min}$ at room 

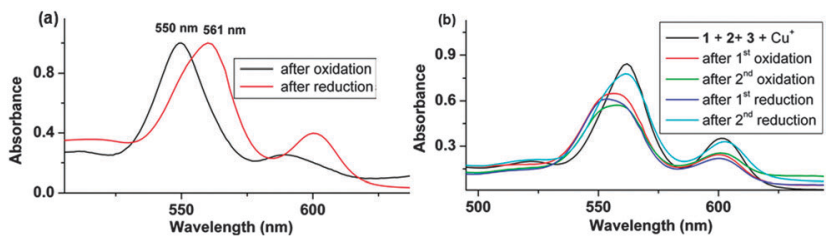

Fig. 2 (a) A solution of $\left[\mathrm{Cu}\left(\mathrm{CH}_{3} \mathrm{CN}\right)_{4}\right] \mathrm{B}\left(\mathrm{C}_{6} \mathrm{~F}_{5}\right)_{4}, \mathbf{1}$ and $\mathbf{2}=1: 1: 1$ at $10^{-4} \mathrm{M}$ in dry DCM was treated with 1 equiv. of $\mathrm{TBPA}^{+} \cdot \mathrm{SbCl}_{6}{ }^{-}$(black trace), then with 1 equiv. of dmfc (red trace, also see the text). (b) UV-Vis changes at the $Q$ band showing the communication between $1-3$ and $\mathrm{Cu}^{+}(1: 1: 1: 1$; at $\left.2 \times 10^{-5} \mathrm{M}\right)$ as a result of two oxidation and two reduction steps (see text).

temperature (Fig. 2a, black trace). The change is in full agreement with a $\mathrm{Cu}^{+}$-induced swing of the nanoarm in $\mathbf{2}$ from the zinc(II) porphyrin to the phenanthroline station and thus formation of $[\mathrm{Cu}(2)]^{+}$and $\mathbf{1}^{+}$. This interpretation was further corroborated by ESI-MS peaks at $m / z=1093.4$ and 1799.2 Da, indicating the presence of switches $\mathbf{1}^{+}$and $[\mathrm{Cu}(2)]^{+}$, respectively (Fig. S20, ESI $\dagger$ ). For a reversal of the process, the above solution was reacted with dmfc (one equiv.). The absorption peak shifted back to $561 \mathrm{~nm}$ and became constant after $18 \mathrm{~h}$ (Fig. 2a, red trace). The ESI-MS spectrum of the solution confirmed the reverse translocation of $\mathrm{Cu}^{+}$as it displays mainly the peak at $m / z=1155.5 \mathrm{Da}$ for $[\mathrm{Cu}(1)]^{+}$and a small one at 1799.2 $\mathrm{Da}$ for $[\mathrm{Cu}(2)]^{+}$, reflecting the starting situation (Fig. S21, ESI $\dagger$ ). To monitor the copper ion transfer by NMR, we chose a soluble $\mathbf{B F D}^{13}$ derivative for reduction of $[\mathrm{Cu}(2)]^{+}$and $\mathbf{1}^{+}$as it produces a diamagnetic oxidation product. The ${ }^{1} \mathrm{H}$ NMR spectrum shows the presence of complexes $[\mathrm{Cu}(\mathbf{1})]^{+}$ and $[\mathrm{Cu}(2)]^{+}$in a ratio of 90:10 (Fig. S18, ESI $\dagger$ ).

Reversible communication between $[\mathrm{Cu}(\mathbf{1})]^{+}$and 3 upon oxidation is more complicated because on the product side the redox potentials, i.e. $E_{1 / 2}\left(1^{0 /+}\right)=450 \mathrm{mV}_{\mathrm{SCE}}$ and $E_{1 / 2}\left([\mathrm{Cu}(3)]^{+/ 2+}\right)=$ $250 \mathrm{mV}_{\mathrm{SCE}}$, invert. ${ }^{6 d}$ As a result, a follow-up redox disproportionation of $\mathbf{1}^{+}$and $[\mathrm{Cu}(3)]^{+}$furnished 1 and $[\mathrm{Cu}(3)]^{2+}$. In the experiment, a $1: 1$ solution of $[\mathrm{Cu}(\mathbf{1})]^{+}$and $3(0.1 \mathrm{mM})$ in DCM was reacted with one equiv. of $\mathbf{T B P A}^{+\bullet} \mathrm{SbCl}_{6}{ }^{-}$and the metal exchange process was monitored at $561 \mathrm{~nm}(\mathrm{Q}$ band of the free nanoswitch 3). The absorption gradually shifted to $550 \mathrm{~nm}$ with full completion after $3 \mathrm{~min}$ (Fig. S23, ESI $\dagger$ ). Metal translocation was ascertained from ESI-MS peaks at 1093.4 and 1876.2 Da attributed to $\mathbf{1}^{+}$and $[\mathrm{Cu}(3)]^{+}$, respectively, but equally a signal at 938.6 Da suggestive of $[\mathrm{Cu}(3)]^{2+}$ was noticed (Fig. S24, ESI $\dagger$ ). After reduction with dmfc ( 1 equiv.) the $\mathrm{Q}$ band was restored at $561 \mathrm{~nm}$ within 3 min (Fig. S23, ESI $\dagger$ ). ESI-MS supported the reversal by showing a signal at 1155.5 Da revealing the formation of $[\mathrm{Cu}(\mathbf{1})]^{+}$(Fig. S25, ESI $\dagger$ ). Similarly, ${ }^{1} \mathrm{H}$ NMR data, now using the $\mathbf{B F D}^{13}$ derivative for reduction, indicate complete reverse translocation of the $\mathrm{Cu}^{+}$from switch $[\mathrm{Cu}(3)]^{+}$to $\mathbf{1}$ (Fig. S22, ESI $\dagger$ ). Thus, the battery of results is clearly in full accord with the required selectivity changes upon oxidation/reduction.

Finally, we focused on stepwise switching with all three nanoswitches being present in solution. In both directions of metal translocation, at first the least stable complex was prepared and then the other switches with increasing binding ability were added sequentially. Thus, to test $\mathrm{Cu}^{+}$transfer, complex $[\mathrm{Cu}(3)]^{+}$ was prepared first, then switches $\mathbf{2}$ and $\mathbf{1}$ were added sequentially,
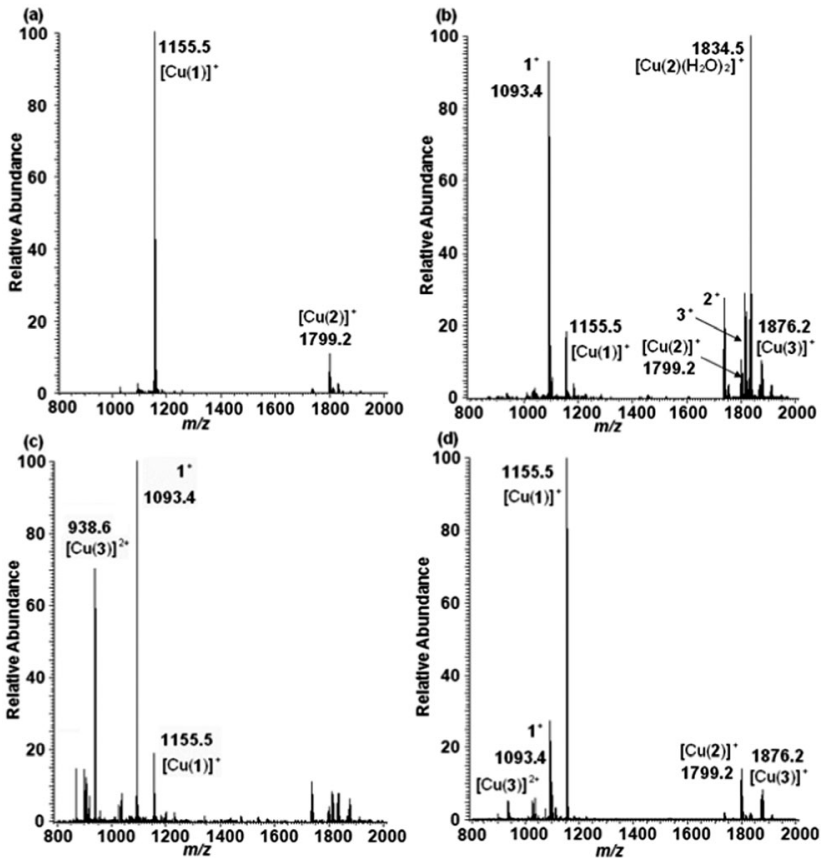

Fig. 3 ESI-MS signature (a) of a solution containing 1, 2, 3 and $\mathrm{Cu}^{+}(1: 1: 1)$ in DCM. The solution after oxidation with (b) one or (c) two equiv. of $\mathrm{TBPA}^{+\bullet} \mathrm{SbCl}_{6}^{-}$. (d) After reduction of (c) with two equiv. of dmfc. Full spectra, see Fig. S28 and S31-S34 (ESI†).

each addition recorded by ${ }^{1} \mathrm{H}$ NMR. After the first addition, ${ }^{6 d}$ a $90: 10$ ratio between $[\mathrm{Cu}(2)]^{+}$and $[\mathrm{Cu}(3)]^{+}$was established (Fig. S26, ESI $\dagger$ ). Finally, after adding 1, a new equilibrium emerged with $[\mathrm{Cu}(\mathbf{1})]^{+}$being formed predominantly in $90 \%$ yield, whereas $[\mathrm{Cu}(2)]^{+}$ was present in only $10 \%$ yield and switch 3 was completely devoid of $\mathrm{Cu}^{+}$ions (Fig. 1e and Fig. S27, ESI $\dagger$ ). Both ${ }^{1} \mathrm{H}$ NMR and ESI-MS spectra, the latter (Fig. 3a) displaying signals at 1155.5 Da for $[\mathrm{Cu}(\mathbf{1})]^{+}$and at 1799.2 $\mathrm{Da}$ for $[\mathrm{Cu}(2)]^{+}$, thus fully match with the data obtained from individual metal complexation studies involving two switches only. A similar protocol was employed for the $\mathrm{Zn}^{2+}$ translocation. As expected, in the presence of all switches, the metal ion distributions were similar to those found in the individual dual-switch studies. As a matter of fact, nanoswitches 1 and 2 remained completely uncomplexed in the presence of $\mathrm{Zn}^{2+}$ with $[\mathrm{Zn}(3)]^{2+}$ being the only coordination complex (Fig. 1f and Fig. S29, ESI $\dagger$ ), also proven from the ESI-MS data showing only one signal at 939.1 Da (Fig. S30, ESI $\dagger$ ).

Lastly, to investigate multistep communication by using only electron transfer as the input, chemical oxidation and reduction steps were implemented (vide supra). For characterisation, we applied the ESI-MS and UV-Vis techniques as each step produced paramagnetic component(s). The equilibrium mixture of switches 1, 2 and 3 in the presence of $\mathrm{Cu}^{+}$(ratio $1: 1: 1: 1$, Fig. 3a) was treated with one equiv. of $\mathbf{T B P A}^{+\bullet} \mathrm{SbCl}_{6}{ }^{-}$and the resulting solution was injected into the ESI-MS instrument. The spectrum (Fig. 3b) shows the presence of $\mathbf{1}^{+},[\mathrm{Cu}(2)]^{+}$, and $\left[\mathrm{Cu}(2)\left(\mathrm{H}_{2} \mathrm{O}\right)_{2}\right]^{+}$, which were assigned from their signals at 1093.4, 1799.2, and 1834.5 Da. Only traces of $[\mathrm{Cu}(\mathbf{1})]^{+}$and $[\mathrm{Cu}(3)]^{+}$were visible at 1155.5 and $1876.2 \mathrm{Da}$, respectively. The relative abundance pattern clearly implies a translocation of $\mathrm{Cu}^{+}$from switch $\mathbf{1}^{+}$ 
to 2 , which goes along with a reorganisation of the arm in 2 from the porphyrin to the phenanthroline station as visible in the UV-Vis spectrum (Fig. 2b, black $\rightarrow$ red trace). Subsequently, the mixture was reacted with one more equivalent of $\mathbf{T B P A}^{+}$• $\mathrm{SbCl}_{6}{ }^{-}$to oxidise $[\mathrm{Cu}(2)]^{+}$, which triggered $\mathrm{Cu}^{2+}$ translocation as seen from ESI-MS signals at $m / z=1093.4$ and 938.6 Da for $\mathbf{1}^{+}$ and $[\mathrm{Cu}(3)]^{2+}$, respectively (Fig. 3c). Despite the reorganisation at both nanoswitches 2 and 3 , the amount of $N \rightarrow$ zinc(II) porphyrin coordination remains in essence constant (Fig. 2b, red $\rightarrow$ green trace). The backward process was initiated by adding one equiv. of dmfc as a reducing agent, which, however, should reduce $\mathbf{1}^{+}$and not $[\mathrm{Cu}(3)]^{2+}$ by oxidation potential considerations. Indeed, no reorganisation of the arm and thus no severe changes in the UV-Vis spectrum were observed (Fig. 2b, green $\rightarrow$ blue trace). Finally, after treatment with one additional equivalent of $\mathbf{d m f c}$ to reduce $[\mathrm{Cu}(3)]^{2+}, \mathrm{Cu}^{+}$ translocation from $[\mathrm{Cu}(\mathbf{3})]^{+}$to $\mathbf{1}$ generated $[\mathrm{Cu}(\mathbf{1})]^{+}$as demonstrated by the ESI-MS spectrum (Fig. 3d). Diagnostically, the process was accompanied by a large nanomechanical reorganisation of the moving arm as evidenced from UV-Vis data at the Q band (Fig. 2b, blue $\rightarrow$ cyano trace). Thus, the trio of nanoswitches has been reset to its initial position after two oxidation and two reduction steps.

Herein, we establish an unprecedented two-step communication cascade between three nanoswitches by programming both metal ion and ligand binding properties depending on their redox states (self-sorting). Ligand oxidation in $[\mathrm{Cu}(\mathbf{1})]^{+}$at $E_{1 / 2}=610 \mathrm{mV}_{\mathrm{SCE}}$ triggered the release of $\mathrm{Cu}^{+}$acting as an input signal for the next switch. Upon second one-electron oxidation at $[\mathrm{Cu}(2)]^{+}\left(E_{1 / 2}=\right.$ $\left.750 \mathrm{mV}_{\mathrm{SCE}}\right){ }^{6 d}$ translocation of $\mathrm{Cu}^{2+}$ changed the switching state of $3 \rightarrow[\mathrm{Cu}(3)]^{2+}$. A two-electron reduction reversed the system to its initial state. Thus, this example not only introduces multistep communication in systems chemistry ${ }^{14}$ but also advances the interconnection of molecular gates and machinery.

We are grateful to the DFG (Schm 647/19-1) and the Universität Siegen for financial support as well as to Kun Chen for the biferrocenylene BFD and Dr T. Paululat for NMR measurements.

\section{Notes and references}

1 D. L. Nelson and M. M. Cox, Lehninger Principles of Biochemistry, W. H. Freeman and Company, New York, 5th edn, 2008.

2 (a) S. G. Bell and B. L. Vallee, ChemBioChem, 2009, 10, 55; (b) H. J. Forman, M. Maiorino and F. Ursini, Biochemistry, 2010, 49, 835.

3 (a) M.-M. Russew and S. Hecht, Adv. Mater., 2010, 22, 3348; (b) Molecular Switches, ed. B. L. Feringa and W. R. Browne, WileyVCH, Weinheim, 2nd edn, 2011; (c) A. C. Fahrenbach, S. C. Warren, J. T. Incorvati, A.-J. Avestro, J. C. Barnes, J. F. Stoddart and B. A. Grzybowski, Adv. Mater., 2013, 25, 331.

4 Some recent reviews: (a) M. von Delius and D. A. Leigh, Chem. Soc. Rev., 2011, 40, 3656; (b) A. Coskun, M. Banaszak, R. D. Astumian, J. F. Stoddart and B. A. Grzybowski, Chem. Soc. Rev., 2012, 41, 19; (c) S. F. M. van Dongen, S. Cantekin, J. A. A. W. Elemans, A. E. Rowan and R. J. M. Nolte, Chem. Soc. Rev., 2014, 43, 99; (d) P. Ceroni, A. Credi and M. Venturi, Chem. Soc. Rev., 2014, 43, 4068.

5 (a) F. M. Raymo and S. Giordani, Org. Lett., 2001, 3, 3475; (b) S. Silvi, E. C. Constable, C. E. Housecroft, J. E. Beves, E. L. Dunphy, M. Tomasulo, F. M. Raymo and A. Credi, Chem. - Eur. J., 2009, $15,178$.

6 (a) S. Silvi, A. Arduini, A. Pochini, A. Secchi, M. Tomasulo, F. M. Raymo, M. Baroncini and A. Credi, J. Am. Chem. Soc., 2007, 129, 13378; (b) H. Kai, S. Nara, K. Kinbara and T. Aida, J. Am. Chem. Soc., 2008, 130, 6725; (c) D. Ray, J. T. Foy, R. P. Hughes and I. Aprahamian, Nat. Chem., 2012, 4, 757; (d) S. Pramanik, S. De and M. Schmittel, Angew. Chem., Int. Ed., 2014, 53, 4709.

7 M. L. Saha, S. De, S. Pramanik and M. Schmittel, Chem. Soc. Rev., 2013, 42, 6860.

8 M. L. Saha, S. Neogi and M. Schmittel, Dalton Trans., 2014, 43, 3815.

9 J.-P. Sauvage, Acc. Chem. Res., 1998, 31, 611.

10 (a) M. M. Safont-Sempere, G. Fernández and F. Würthner, Chem. Rev., 2011, 111, 5784; (b) M. L. Saha and M. Schmittel, Org. Biomol. Chem., 2012, 10, 4651.

11 S. Kume and H. Nishihara, Chem. Commun., 2011, 47, 415.

12 (a) M. Schmittel, S. De and S. Pramanik, Angew. Chem., Int. Ed., 2012, 51, 3832; (b) M. Schmittel, S. Pramanik and S. De, Chem. Commun., 2012, 48, 11730; (c) S. De, S. Pramanik and M. Schmittel, Dalton Trans., 2014, 43, 10977.

13 -(11-Bromoundecyl)-1, $1^{\prime}$-biferrocenylene is used in this study as a reductant. $E_{1 / 2}(\mathbf{B F D})=0.09 \mathrm{~V}_{\mathrm{SCE}}$ and $E_{1 / 2}\left(\mathbf{B F D}^{+\bullet}\right)=0.76$ $\mathrm{V}_{\mathrm{SCE}}($ see $(a)$ R. Breuer and M. Schmittel, Organometallics, 2012, 31, 6642; (b) R. Breuer and M. Schmittel, Organometallics, 2013, 32, 5980).

14 J. R. Nitschke, Nature, 2009, 462, 736. 